\title{
CENTROS DE INTERNAMIENTO DE EXTRANJEROS. PRINCIPALES DENUNCIAS Y NOVEDADES LEGISLATIVAS
}

\author{
MIGRANTS' DETENTION CENTERS. MAIN COMPLAINTS AND \\ LEGISLATIVE NOVELTIES
}

\author{
Carmen Azcárraga Monzonís \\ Universidad de Valencia. España/Spain \\ carmen.azcarraga@uv.es
}

Recibido/Received: 11/08/2014

Modificado/Modified: 21/08/2014

Aceptado/Accepted: 23/09/2014

\section{RESUMEN}

Los centros de internamiento de extranjeros fueron creados en España hace casi treinta años con la primera Ley de Extranjería y han constituido desde entonces un controvertido mecanismo de control de la política migratoria objeto de críticas y denuncias por la constante vulneración de derechos de los extranjeros que se han constatado. En marzo de 2014 se aprobó un nuevo Reglamento de funcionamiento y régimen interior de estos centros que pretende clarificar su régimen jurídico. En este estudio realizaremos un repaso de las principales denuncias que existen contra ellos y analizaremos algunos de los aspectos de la nueva regulación que hemos considerado más relevantes.

\section{PALABRAS CLAVE}

Centro de internamiento de extranjeros, derecho, denuncia, reglamento.

\section{SUMARIO}

1. Presentación. 2. Los centros de internamiento de extranjeros desde dentro: principales denuncias y recomendaciones. 3. El nuevo reglamento de funcionamiento y régimen interior de los centros de internamiento de extranjeros. 4. Valoración final. Bibliografía.

\begin{abstract}
Migrants' detention centers were created in Spain almost thirty years ago under the first Immigration Law and have constituted since then a controversial mechanism of control of immigration policy due to the frequent violation of rights of foreigners which have been evidenced. A new regulation on the functioning and internal regime of such centers was approved in March 2014 with the objective of clarifying their legal regime. This research aims at providing an overview of the main complaints against these centers and some of the most important aspects of the new regulation.
\end{abstract}

\section{KEYWORDS}

Migrants' detention center, right, complaint, regulation.

\section{CONTENTS}

1. Presentation. 2. Centers for foreigners from within: main complaints and recommendations. 3. The new operating regulations and internal rules of the centers for foreigners. 4. Final Rating. References 


\section{PRESENTACIÓN}

Los centros de internamiento de extranjeros (CIE) constituyen desde su creación un tema controvertido ante la amenaza que suponen para el ejercicio de los derechos que el ordenamiento jurídico confiere a los extranjeros, y ello tanto en España como en todos los países en los que se contemplan como un elemento de control de la política migratoria. Este tipo de centros se han multiplicado con el tiempo hasta convertirse en un fenómeno social global (Valluy, 2005:). Sólo en la Unión Europea existen más de 250 de lugares de internamiento de extranjeros (Miralles, 2012:733), ocho de ellos en España (cinco en la península y tres en Canarias) con un total de 2.572 plazas (2.346 para hombres y 226 para mujeres).

Hace unos años en nuestro país, la muerte de dos internos en un corto espacio de tiempo, Samba Martine el 19 de diciembre de 2011 en el CIE de Aluche (Madrid) e Ibrahim Sissé el 6 de enero de 2012 en el de Zona Franca (Barcelona), situó esta problemática en el centro de la opinión pública, sumando estas dos tragedias a otras que se han ido sucediendo en distintos centros en los últimos años. Parte de la ciudadanía ni siquiera conocía su existencia, lo que constituye una muestra más de la opacidad que rodea a estas instituciones.

Los CIE son establecimientos que funcionan como prisiones en la práctica aunque rehúyan en el papel de la calificación de penitenciarios. Señala el art. 60.2 de la Ley Orgánica 4/2000, de 11 de enero, sobre derechos y libertades de los extranjeros en España y su integración social (LOEx, BOE núm. 10 de 12 de enero de 2000) -relativo al internamiento por denegación de entrada si el regreso al punto de origen se retrasa más de setenta y dos horas-, que "los lugares de internamiento para extranjeros no tendrán carácter penitenciario, y estarán dotados de servicios sociales, jurídicos, culturales y sanitarios".

En la misma línea, según el art. 62 bis.1 LOEx los CIE son "establecimientos públicos de carácter no penitenciario", en los que el ingreso y la estancia "tendrán únicamente finalidad preventiva y cautelar", debiéndose salvaguardar durante el internamiento los derechos y libertades reconocidos en el ordenamiento jurídico "sin más limitaciones que las establecidas a su libertad ambulatoria, conforme al contenido y finalidad de la medida judicial de ingreso acordada".

A pesar de lo anterior, constataremos en este trabajo cómo de acuerdo con numerosos informes y denuncias tanto de organizaciones de apoyo a inmigrantes como de los propios internos, no se cumplen dichas previsiones. No se está acordando el internamiento en estos centros únicamente con finalidad preventiva y cautelar, con el objetivo de garantizar la expulsión (gubernativa o judicial). No se están salvaguardando los derechos y libertades de los extranjeros internos más allá de la privación de libertad, habiéndose documentado incluso situaciones de abuso policial. Y tampoco se proporcionan adecuadamente los servicios sociales, jurídicos, culturales y sanitarios legalmente contemplados. Son prisiones encubiertas en las que teóricamente se ejecutan medidas cautelares, en condiciones más duras que en las cárceles españolas como vienen denunciando las organizaciones civiles que desempeñan dentro de los CIE una meritoria labor como ojos de la sociedad y voz de los internos.

Hoy, la novedad legislativa que justifica esta contribución es la anunciada aprobación del Real Decreto 162/2014, de 14 de marzo, por el que se aprueba el Reglamento de funcionamiento y régimen interior de los centros de internamiento de extranjeros (BOE núm. 64, de 15 de marzo de 2014), un texto de desarrollo que ve la luz casi treinta años después del nacimiento de esta figura. Los CIE se crearon en 1985 con la adopción de la primera Ley de extranjería: la Ley Orgánica 7/1985, de 1 de julio, sobre derechos y libertades de los 
extranjeros en España (BOE núm. 158, de 3 de julio de 1985), norma que contemplaba la posibilidad de que el juez de instrucción acordara el internamiento como medida cautelar vinculada a la sustanciación o ejecución de un expediente de expulsión.

El funcionamiento de estos espacios de internamiento fue objeto de la correspondiente regulación en el Reglamento de ejecución de la Ley Orgánica 7/1985, de 1 de julio, aprobado por el Real Decreto 155/1996, de 2 de febrero (BOE núm. 47, de 23 de febrero de 1996) y en la Orden del Ministerio de Presidencia de 22 de febrero de 1999 (BOE núm. 47, de 24 de febrero de 1999), dictada en cumplimiento de la habilitación contenida en el referido Real Decreto. Tal Orden ministerial se ha venido aplicando hasta el momento actual, lo cual se ha considerado "gravísimo" desde un punto de vista jurídico por cuanto dicha normativa de rango menor ha estado restringiendo derechos fundamentales de los internos como el derecho a la intimidad, el derecho a la libertad personal o el derecho a las comunicaciones privadas (Nogueras et al. 2001:897).

Más adelante, se aprobaría la actual LOEx, modificada en diversas ocasiones, y el Reglamento de desarrollo actualmente en vigor, aprobado por el Real Decreto 557/2011, de 20 de abril (BOE núm. 103, de 30 de abril de 2011). La LOEx contempla la posibilidad del internamiento en diversas situaciones proporcionando una regulación "un tanto asistemática y confusa" de la que se ha considerado la medida cautelar más importante en materia de extranjería por la potencia limitadora de derechos fundamentales que posee (Ortega, 2005:71).

En una de las reformas de la LOEx, operada por la Ley Orgánica 2/2009, de 11 de diciembre (BOE núm. 299, de 12 de diciembre de 2009), se recogía el mandato expreso dirigido al Gobierno desde la Disposición Adicional Tercera para que aprobara, en el (incumplido) plazo de seis meses, un Reglamento que desarrollara el régimen de internamiento de los extranjeros y que sustituyera de este modo definitivamente a la mencionada Orden ministerial de 1999.

Tal mandato ha sido cumplido recientemente con la aprobación de la nueva normativa, novedad que ha venido impulsada asimismo por la actividad del legislador europeo, ya que con la aprobación del nuevo Reglamento se ha procedido a incorporar al Derecho nacional diversos aspectos regulados por la denominada en su momento por sectores críticos "Directiva de la vergüenza", esto es, la Directiva 2008/115/CE del Parlamento Europeo y del Consejo, de 16 de diciembre de 2008, relativa a normas y procedimientos comunes en los Estados miembros para el retorno de los nacionales de terceros países en situación irregular (DOUE L 348, de 24 de diciembre de 2008).

Se considera positivo que se haya dotado (por fin) a estos centros de una regulación específica, considerada por muchos urgente y necesaria, con el fin de clarificar su funcionamiento así como los derechos y deberes de los internos, la mejora de sus condiciones de vida durante los sesenta días de internamiento que como máximo contempla la legislación vigente (art. 62.2 LOEx), y las funciones y la formación de los trabajadores. Cuestión diferente es que la nueva normativa vaya a cambiar la realidad y el funcionamiento de los CIE en la práctica, claramente mejorable tanto desde un punto de vista jurídico como humano.

El nuevo Reglamento codifica algunas cuestiones no reguladas anteriormente, pero retoma otras que ya se contemplaban sin incorporar lo dispuestos por los autos emitidos por los Juzgados de control. La ausencia de regulación no era pues el único problema, sino el alto grado de incumplimiento de la normativa existente hasta el momento y de las directrices judiciales de los órganos judiciales encargados de supervisar su funcionamiento. A pesar de 
lo anterior, no es menos cierto que la aprobación del nuevo Reglamento viene a colmar un vacío legal inexcusable y supone la principal novedad legislativa en la materia.

Hasta este momento la normativa existente era a todas luces insuficiente, lo que ha favorecido estos años la falta de transparencia e impunidad en la actuación de las autoridades en unas instituciones en las que se limitan y vulneran derechos. Abordaremos seguidamente las principales denuncias en torno a la adopción y ejecución de esta medida en este tipo de centros, para a continuación subrayar algunos aspectos del nuevo Reglamento que hemos considerado más relevantes.

\section{LOS CENTROS DE INTERNAMIENTO DE EXTRANJEROS DESDE DENTRO: PRINCIPALES DENUNCIAS Y RECOMENDACIONES}

Desde su creación en los años 80 muchas voces han cuestionado y denunciado la mera existencia de los CIE y su controvertido funcionamiento. Esta contribución pretende poner de relieve algunas de las muchas críticas que han recibido, cuestiones muchas de ellas que se configuran en la ley como derechos de los internos pero que son violados sistemáticamente.

En primer lugar, situándonos en el inicio mismo del proceso, desde que se acuerda adoptar la medida cautelar de internamiento, se ha reprochado que lo que debería constituir una opción última dirigida a un fin concreto (ejecutar la expulsión) se convierte en no pocas ocasiones en la única medida contemplada (1). Una vez dentro del CIE, se suceden otras críticas de diferente naturaleza. Proponemos abordar tres de ellas. Por un lado, la problemática derivada de que extranjeros con perfiles muy dispares y necesidades distintas compartan los mismos espacios (2). Por otro lado, las deficientes condiciones en las que se encuentran las instalaciones en las que se ubican los centros, así como de los servicios prestados en los mismos (3). Y por último, las graves denuncias contra los funcionarios de policía que ejercen sus funciones en estos centros de abuso, maltrato, vejaciones e incluso agresiones (4).

Finalizaremos este apartado reproduciendo las propuestas y recomendaciones realizadas por algunas organizaciones a la luz de los problemas que se habrán constatado, aunque el lector irá comprobando cómo las críticas y las propuestas se irán sucediendo a lo largo de todo el trabajo.

\section{Medida cautelar tendente a garantizar la expulsión}

La medida cautelar de internamiento se articula en la legislación española con una finalidad concreta: asegurar y finalmente ejecutar la expulsión del territorio español del extranjero al que se interna, objetivo que comparten los distintos supuestos en que se prevé la posibilidad de acordar esta medida: internamiento adoptado en el marco de un expediente sancionador, internamiento consecutivo a devolución o retorno cuando no se puedan ejecutar en 72 horas, internamiento como consecuencia de la aplicación de la normativa penal cuando se acuerde la expulsión como sustitución de la pena. Entre estos supuestos, nos gustaría sumarnos a los que vienen reivindicando la gravedad y desproporción que supone privar de libertad a extranjeros que no han cometido infracción penal alguna; personas que se hallan en España o que intentan entrar en nuestro país en busca de una oportunidad vital que no les brinda su país de origen.

En este último marco, señala el art. 62.1 LOEx que incoado el expediente sancionador en alguno de los supuestos que relaciona en el que pueda proponerse la expulsión -por ejemplo, encontrarse irregularmente en territorio español, por no haber obtenido la prórroga de 
estancia, carecer de autorización de residencia o tener caducada más de tres meses la mencionada autorización, y siempre que el interesado no hubiere solicitado la renovación de la misma en el plazo previsto reglamentariamente (art. 53.1.a) LOEx)-, el instructor podrá solicitar al Juez de Instrucción competente que disponga el ingreso del extranjero en un centro de internamiento en tanto se realiza la tramitación del expediente sancionador.

A continuación, corresponde al Juez, previa audiencia del interesado y del Ministerio Fiscal, resolver la adopción o no de dicha medida, mediante auto motivado, en el que deberá atender a una serie de consideraciones impuestas por la propia Ley (art. 62.1.II LOEx). Primero, se exige atender al principio de proporcionalidad, tomando en consideración las circunstancias concurrentes. Segundo y, en especial, deberá considerar diferentes extremos: el riesgo de incomparecencia por carecer de domicilio o de documentación identificativa, las actuaciones del extranjero tendentes a dificultar o evitar la expulsión, así como la existencia de condena o sanciones administrativas previas y de otros procesos penales o procedimientos administrativos sancionadores pendientes. Y por último, deberá también valorar los casos de enfermedad grave, riesgo del internamiento para la salud pública o la salud del propio extranjero.

Junto con estos aspectos, se ha considerado que el instructor debería proporcionar al Juez otros aspectos que le permitieran valorar más adecuadamente la adopción de esta medida. Concretamente, si el extranjero tiene parientes en territorio español, los medios de vida con los que cuenta, los intentos, en su caso, de regularizar su situación, el grado de integración cultural en España, y cualquier otra circunstancia que le permita evaluar su posible arraigo en nuestro país (García, 2002:385).

Por lo tanto, establece la ley española que es posible adoptar la medida de internamiento en tal situación valorando los aspectos mencionados. Pero el art. 61 LOEx señala también que al incoar un procedimiento sancionador en el que pueda proponerse la expulsión, el instructor, a fin de asegurar la resolución final que pudiera recaer, podrá adoptar otro tipo de medidas; alguna de las que se enumeran en esta disposición: presentación periódica ante las autoridades competentes, residencia obligatoria en determinado lugar, retirada del pasaporte o documento acreditativo de su nacionalidad previa entrega al interesado del resguardo acreditativo de tal medida, detención cautelar por la autoridad gubernativa o sus agentes por un período máximo de 72 horas previas a la solicitud de internamiento (en cualquier otro supuesto de detención, la puesta a disposición judicial se producirá en un plazo no superior a 72 horas), internamiento preventivo previa autorización judicial en los centros de internamiento, o cualquier otra medida cautelar que el juez estime adecuada y suficiente.

El "internamiento preventivo" en un CIE constituye pues sólo una medida más de las contempladas en la legislación para la finalidad perseguida, por lo que teniendo en cuenta las secuelas físicas y psicológicas y las consecuencias familiares que puede entrañar para las personas la privación de libertad en las condiciones que describiremos en el siguiente epígrafe, resulta pertinente adelantar en este momento dos importantes conclusiones. Primera, entendemos que la mera existencia de estos centros no se justifica; y, segunda, ante su existencia y probable continuidad, es evidente que debería adoptarse el internamiento únicamente en aquellas situaciones en que realmente exista una certeza de expulsión en el plazo fijado por la ley. Sin embargo, la práctica demuestra cómo se adoptan internamientos en casos en los que no existe evidencia alguna de que se vaya a poder ejecutar la expulsión.

Así lo ha hecho constar el Defensor del Pueblo en su calidad de Mecanismo Nacional de Prevención de la Tortura y otros tratos o penas crueles, inhumanos o degradantes (MNP) encargado de la supervisión del respeto de los Derechos Humanos en los centros de privación 
de libertad, en atención a la previsión establecida en el Protocolo facultativo a la Convención de Naciones Unidas contra la tortura y otros tratos o penas crueles, inhumanos o degradantes (OPCAT), hecho en Nueva York el 18 de diciembre de 2002. De acuerdo con el Informe anual del MNP publicado en 2013, del total de los 49.406 ciudadanos extranjeros detenidos ese año, 9.002 fueron internados en los distintos CIE; y de ese total de internados, fueron expulsados 4.726 personas. Ello supone que el 47,51\% de los extranjeros internos en CIE españoles fueron puestos en libertad al no conseguir expulsarles, cifra similar a la del año 2012, siempre según este mismo Informe.

Es por tanto evidente que si casi el $50 \%$ de los extranjeros internados no son expulsados, no se está adoptando el internamiento cuando resulta estrictamente indispensable, como así exigió el Tribunal Constitucional en el Fundamento Jurídico $1^{\circ}$ de la Sentencia núm. 115/87, de 7 de julio (Campo, 2001:452). Tal sentencia fue dictada en el recurso de inconstitucionalidad núm. 880/1985 promovido por el Defensor del Pueblo contra los arts. 7, 8, 26 y 34 de la Ley Orgánica 7/1985, primera Ley de extranjería. La sentencia declaró constitucional el internamiento de extranjeros pero recordó que éste "debe regirse por el principio de excepcionalidad, sin menoscabo de su configuración como medida cautelar" (STC 41/1982, de 2 de julio) y que "este carácter excepcional exige la aplicación del criterio hermenéutico del favor libertatis, lo que supone que la libertad debe ser respetada salvo que se estime indispensable la pérdida de libertad del extranjero por razones de cautela o de prevención, que habrán de ser valoradas por el órgano judicial”.

De igual modo resulta imperativo recordar que la propia legislación de extranjería establece en el art. 62.2 LOEx que "el internamiento se mantendrá por el tiempo imprescindible para los fines del expediente" (siendo su duración máxima de sesenta días) y que el apartado siguiente ordena la puesta inmediata en libertad del extranjero "cuando hayan dejado de cumplirse las condiciones descritas en el apartado 1" de dicho precepto.

Ya vimos cómo la adopción de esta medida por el Juez competente demanda que éste aplique el principio de proporcionalidad, así como que tome en consideración una serie de factores anteriormente mencionados. Pero una vez adoptada la medida, si las condiciones que condujeron a su internamiento dejan de existir se exige que el extranjero sea puesto inmediatamente en libertad por la autoridad administrativa que lo tenga a su cargo, poniéndolo en conocimiento del Juez que autorizó su internamiento, aunque también podrá ser ordenado del mismo modo y por las mismas causas, por el Juez, de oficio o a iniciativa de parte o del Ministerio Fiscal.

A estos efectos se han citado una serie de "motivos obstativos" más usuales que pueden conducir a esta situación. Por ejemplo, la negativa de reconocimiento de la condición de nacional de un Estado por su Embajada o Consulado (con la consecuencia de no entrega de salvoconductos), la acreditación de presupuestos excluyentes de la expulsión, la falta de autorización de la expulsión por parte de una autoridad judicial de la que depende una causa penal activa contra el extranjero internado o la suspensión cautelar de la expulsión por la jurisdicción contencioso-administrativa (Fernández, 2013:534). De darse alguna de esas situaciones, el extranjero ha de ser liberado.

No obstante, también procede denunciar que con ello tampoco queda resuelto el problema. Cuando los extranjeros son puestos en libertad pasados, como máximo, los sesenta días de encierro, quedan en un limbo jurídico difícil de entender. Quedan en libertad, en la calle, porque no son expulsables; pero tampoco pueden regularizar su situación al salir. Se les condena por tanto a una suerte de muerte civil cuya situación administrativa, si es que es posible hablar de tal situación, ha quedado con el tiempo vacía de derechos. 


\section{Convivencia de distintos grupos de extranjeros}

Los migrantes retenidos en los CIE coinciden en carecer de la documentación necesaria para residir legalmente en España, pero presentan al mismo tiempo diferencias notables respecto de sus condiciones personales, laborales, políticas, sociales y culturales. Esta realidad permite percibir que en estos centros conviven diversos perfiles de extranjeros, habiéndose identificado cuatro grupos principales (Jarrín et al. 2012:8):

1) Migrantes interceptados en la travesía. Se clasifican dentro de este grupo principalmente las personas procedentes de África subsahariana que viajan en embarcaciones hasta las costas españolas y son interceptadas cuando intentan llegar a territorio español. Según estos autores, los CIE se conciben para estas personas como la puerta de entrada a Europa, subrayándose además que siguen como una estrategia frecuente viajar sin documento indicativo de la nacionalidad para impedir su deportación.

2) Migrantes que han cumplido pena de cárcel. Propondríamos agrupar en esta categoría a un conjunto más amplio de personas, incluyendo no sólo los internados en un CIE tras haber cumplido condena en España a la espera de ser expulsados (art. 57.8 LOEx) -en este caso se ha denunciado la "doble sanción" que supone entrar en un CIE tras salir de la cárcel-, sino también los extranjeros que han sido condenados pero han visto sustituida la condena de pena de prisión inferior a seis años por la expulsión del país (art. 89 del Código Penal). Se trata por tanto de personas que han incurrido en conductas perseguidas por la legislación penal.

3) Migrantes con irregularidad sobrevenida. Este grupo se refiere a aquellos extranjeros que habiéndose encontrado en situación regular en nuestro país, han perdido tal estatus, convirtiéndose en irregulares expulsables. Por ejemplo, aquéllos que entraron con visado de turista y permanecen en nuestro país transcurrido el plazo de estancia legal; o aquéllos otros que no consiguen renovar su autorización de residencia.

4) Migrantes en situación irregular establecidos en España. Se incluyen en esta categoría los extranjeros que han entrado en el país de forma irregular o clandestina, y permanecen en el mismo en situación irregular o incluso trabajando sin la autorización correspondiente.

Identificados estos cuatro grupos, se pretende resaltar en este punto la problemática que pueda suponer reunir en un mismo espacio a personas con perfiles tan dispares. Sobre todo a personas condenadas penalmente con otras que se encuentran encerradas por un ilícito administrativo. Además de la potencial tensión que puede surgir en espacios cerrados sin libertad ambulatoria (situaciones de estrés, ansiedad y demás sensaciones asociadas a vivir una situación semejante), las organizaciones relatan la angustia de aquéllos que se preguntan por qué se encuentran allí retenidos si no han cometido delito alguno, por qué les esposan en los traslados, siendo una de sus demandas principales precisamente que se distribuyan en pabellones separados a los extranjeros que han cometido delitos y a los que no (o tal vez que los que hayan cometido infracciones penales esperen la expulsión en centros penitenciarios y no en un CIE), ya que se ha constatado cómo la convivencia de ambos colectivos provoca conflictos y el incremento de la tensión.

A lo anterior nos gustaría añadir la situación de dos colectivos que se caracterizan por su especial vulnerabilidad y por la necesidad de que las autoridades españolas tengan una actitud activa en su detección y protección con el fin de preservar los derechos de los que podrían ser titulares. Nos referimos a los potenciales solicitantes de asilo y a las víctimas de trata de seres humanos. En cuanto a los primeros, muchos extranjeros desconocen la posibilidad de ejercer el derecho de asilo ante la ausencia de información por parte de las autoridades españolas. De hecho, la Comisión Española de Ayuda al Refugiado (CEAR) constató en el Informe "Situación de los centros de internamiento para extranjeros en España. 
Conversaciones junto al muro" de diciembre de 2009 que en ninguno de los tres centros visitados para la elaboración de este informe (Madrid, Málaga y Valencia) se proporcionaba información espontánea sobre derecho de asilo, lo que agrava el panorama que venimos describiendo.

En relación con las víctimas de trata, la situación de internamiento que viven estas víctimas conlleva una mayor situación de vulnerabilidad, a lo que se suma que el mero hecho de que se encuentren en un CIE es consecuencia del incumplimiento por parte del Estado español de obligaciones derivadas de la legislación vigente (art. 59 bis LOEx), como la obligación de identificar con personal formado y cualificado. El estudio "Mujeres en el CIE: género, inmigración e internamiento" de 2013 considera una "dramática" conclusión haber constatado la presencia en el CIE de Aluche de mujeres víctimas de trata con fines de explotación sexual, que en la mayoría de casos pasan inadvertidas por el centro sin ser detectadas (Martínez, 2013:38).

Si no se detectan, tampoco pueden beneficiarse del régimen que prevé la legislación de extranjería en estos casos, que supone para el Estado, entre otras obligaciones, la de no devolver a la víctima en caso de peligro a la vida o integridad de la persona, reconocer el derecho a un periodo de reflexión no condicionado a la cooperación con las autoridades, prestar asistencia y apoyo a las víctimas, retorno asistido y seguro o conceder autorización de residencia y trabajo a elección de la víctima, etc.

\section{Deficiencias en las instalaciones y los servicios}

Las deficiencias de las instalaciones en las que se ubican los CIE y los servicios en ellos prestados repercuten seriamente en una constante vulneración de derechos de los internos. Los Informes mencionados a lo largo de este trabajo y otros que constan en la bibliografía aneja dan cuenta de situaciones realmente alarmantes. Mencionaremos algunas de ellas en términos generales, sin referirnos a ningún CIE en particular salvo mención expresa ni asegurar que se trate de violaciones sistemáticas y continuas. Merecen no obstante ser difundidas dada su gravedad tras haber sido documentadas.

Empezaremos por ejemplo por mencionar las condiciones en que se encuentran algunos dormitorios, o, siendo más precisos, las condiciones de algunas celdas. Se describen espacios mal acondicionados, sucios, con literas precarias y carentes de armarios ni taquillas donde dejar las pertenencias seguras bajo llave, teniendo que dejar sus objetos personales en el suelo. Se han identificado asimismo casos de internos durmiendo en el suelo por el hacinamiento de ciertos centros, lo cual es vergonzoso. Tampoco se justifica de ningún modo que no se les proporcione o que tengan dificultades para obtener ropa, calzado y productos de higiene, y que la ausencia de sábanas suponga utilizar por las noches unas mantas que provocan importantes erosiones en la piel, situación que se agrava por la deficiente asistencia médica proporcionada en los centros, como veremos después.

Por otro lado, forma parte de la dignidad que merece toda persona que los internos puedan hacer uso de los lavabos con privacidad y a cualquier hora del día, mientras, por el contrario, se han denunciado casos en que los internos han tenido que hacer sus necesidades dentro de la celda por las noches en el mismo lavamanos que al día siguiente han tenido que usar para lavarse ante la imposibilidad de salir a determinadas horas a los servicios, los cuales, además, no permiten en algunos centros que los internos puedan disfrutar de intimidad alguna.

Algo similar ocurre respecto al uso de las salas de visita cuando reciben a familiares $u$ otras personas, donde además de no gozar de la privacidad necesaria se añade en algunos centros la prohibición de contacto físico por la presencia de mamparas acristaladas y el escaso tiempo permitido. Destacaremos también la falta de control de una temperatura 
adecuada en cada época del año, la ausencia de espacios preparados para lavar y tender la ropa, la falta de materiales de ocio y lectura y las insuficientes condiciones de salubridad y limpieza en general.

Por lo que respecta a los servicios prestados en los CIE, se han detectado deficiencias, entre otros, en los servicios relacionados con el ejercicio de la libertad religiosa, en la mediocre y escasa alimentación proporcionada, en la falta de asistencia de intérpretes y de personal con conocimientos de idiomas, en la ausencia de asistencia social, y nos gustaría detenernos por su gravedad en la deficiente asistencia sanitaria.

Las organizaciones han documentado en este último ámbito situaciones habituales en algunos de estos centros que son ciertamente intolerables. En términos generales, se ha denunciado que no existe asistencia sanitaria permanente; además los horarios médicos son restringidos, las citas escasas y de corta duración, los diagnósticos y tratamientos poco especializados (ausencia de atención psiquiátrica, ginecológica u odontológica, por ejemplo), y existe incluso falta de atención a pesar de solicitarlo en repetidas ocasiones. Asimismo no se elaboran historias clínicas, no se realizan analíticas destinadas a detectar ciertas enfermedades, y el personal cualificado no siempre habla el idioma de los pacientes, lo que sumado a la ausencia de intérpretes, hace extremadamente difícil la comunicación en situaciones tan sensibles.

En otro orden de cosas, no queremos dejar de mencionar la condenable práctica que supone la falta de notificación a los internos del momento en que van a ser expulsados, la localidad de destino de la expulsión, los datos del vuelo cuando sea por vía aérea, etc., con la consecuente falta de previsibilidad e imposibilidad de organización familiar que eso supone en muchas ocasiones, por no hablar de la angustia que tal situación puede producir en la persona interesada a lo largo de dos meses. Parece una obviedad reclamar que los internos han de estar informados sobre todo aquello que les pueda afectar.

Han de recibir información suficiente y en un idioma que comprendan (es necesario reforzar la asistencia de intérpretes) de los motivos por los que han sido encerrados, los derechos y deberes que ostentan en el CIE, del derecho de asilo -como reclamábamos antes-, la forma de contactar a sus abogados, la posible formulación de quejas, la existencia de los Juzgados de control a los que se pueden dirigir, la prestación de servicios dentro del CIE a los que tienen derecho, el momento y demás datos de su expulsión, etc. Asimismo no siempre reciben al abandonar el centro un certificado en el que consten los días que han permanecido encerrados, documento probatorio imprescindible a los efectos de evitar un reingreso que quede fuera de la ley -tendremos la oportunidad de profundizar sobre el reingreso más adelante-.

Por lo que respecta a la situación de las mujeres en los CIE, indica el Informe de CEAR de 2009 que en éstos conviven un $85 \%$ de hombres y un $15 \%$ de mujeres, siendo éste un colectivo con unas necesidades específicas no siempre atendidas en estos centros y que dan lugar a discriminaciones por motivos de género. Por ejemplo, señala la organización Women's Link Worldwide en el Informe "Mujeres en los centros de internamiento de extranjeros. Realidades entre rejas" de 2012, que se han documentado casos en que disfrutan de un menor tiempo de recreo en el patio que el de sus compañeros varones, los módulos de mujeres cuentan con menores y más deficientes espacios comunes y de ocio y en ocasiones tienen que encargarse ellas mismas de la limpieza de las instalaciones en su módulo.

Especialmente importante resulta, por otro lado, el acceso a la salud de las mujeres, y en particular las deficiencias detectadas en el ejercicio de los derechos sexuales y reproductivos. Así, se ha podido documentar que las mujeres que se encuentran embarazadas en los CIE no 
reciben una atención médica especializada, por lo que no se les practican los controles periódicos preceptivos que garanticen la salud tanto de la mujer como del feto. Asimismo tampoco se les proporciona información sobre los supuestos en que pueden acceder a la interrupción voluntaria del embarazo e incluso algunas organizaciones han denunciado haber detectado casos de abortos y de mujeres embarazadas en mal estado de salud.

Algunas internas han sufrido además violencia verbal y física relacionada con su condición de mujeres, como comentaremos en el siguiente apartado.

\section{Abuso policial}

En el Informe CEAR de 2009 se considera que el trato del personal a los internos es uno de los temas más delicados en los CIE. De acuerdo con datos proporcionados en este estudio, relativo a los CIE de Madrid, Málaga y Valencia, la mayoría de internos evalúa el trato como adecuado. No obstante, alrededor de uno de cada cuatro internos considera que existen malos tratos por parte de policías y funcionarios que, a título individual, tienen actitudes vejatorias, con gritos, maltratos o golpes. Se estima en este trabajo que un $32 \%$ de internos considera sufrir un trato negativo dentro del centro, que incluiría violencia física y verbal, y un 17,7\% consideran que existe algún tipo de discriminación por ser de piel negra, árabe u otras razones. Se refleja asimismo que la queja más generalizada en el CIE de Valencia es de maltrato selectivo hacia los detenidos magrebíes, opinión expresada incluso por personas no pertenecientes a ese colectivo.

Añade el Informe de la Asociación Pro Derechos Humanos de España de febrero de 2013 "Centros de internamiento de extranjeros en España" en relación con el CIE de Madrid que existe un clima general de hostilidad de los agentes de policía que custodian el centro, vejaciones verbales y escaso tacto y experiencia en el manejo de situaciones de conflicto. Destaca asimismo que la propia Dirección del centro admitió que en general se trata de un destino de trabajo que no satisface a los agentes, quienes, además cuentan en gran medida con escasa experiencia laboral.

En estos mismos estudios se relacionan además graves evidencias de malos tratos, agresiones y torturas en los centros de Madrid y Valencia. Los violentos episodios descritos son escandalosos y no deben quedar impunes. Con este fin se han presentado por los propios internos y por los colectivos de apoyo un importante número de quejas ante las autoridades competentes, denuncias que dan lugar a la incoación de los correspondientes procesos pero cuya investigación se encuentra con múltiples trabas.

Pueblos Unidos destaca los siguientes obstáculos en el Informe "Atrapados tras las rejas. Informe 2012 sobre los centros de internamiento de extranjeros (CIE) de España": imposibilidad de identificar a los funcionarios de policía por el incumplimiento de la obligación de ir correctamente identificados, ausencia de grabaciones en vídeo que permitan confirmar (o desmentir, en su caso) la existencia de los malos tratos denunciados -buena parte de estos hechos tienen lugar precisamente en espacios sin video vigilancia-, ausencia de la propia víctima -los extranjeros que declaran haber sufrido agresiones policiales suelen ser finalmente expulsados, lo que dificulta la ratificación de su testimonio ante el Juez-, interposición de contradenuncias por parte de la policía por el mismo motivo y la falta de competencia de los Juzgados de control para instruir las quejas que reciben por hechos presuntamente delictivos.

Por otra parte, no queremos desaprovechar la oportunidad que supone dar a conocer que en los CIE se imponen castigos individuales y colectivos y que existen celdas de aislamiento a tal fin (o "habitaciones individuales" según el eufemismo usado por el art. 62 quinquies apartado 2 LOEx y el art. 34.2 de la Orden Ministerial de 1999). La publicación de 2013 
“¿Cuál es el delito? Informe de la Campaña por el cierre de los centros de internamiento: el caso de Zapadores" relata un episodio acontecido en la Nochebuena de 2010 en el centro de Valencia en el que un grupo de internos fue obligado a salir al patio en plena noche sin ropa de abrigo y a mantener un tiempo los brazos en alto. Los hechos fueron puestos en conocimiento del Juzgado de vigilancia del CIE, que remitió a reparto los hechos que pudieran ser constitutivos de infracción penal, pero la investigación quedó frustrada por la expulsión de los testigos del suceso, quienes además denunciaron malos tratos. Finalmente la causa fue archivada.

Terminaremos este punto señalando que las mujeres ven agravada su situación ante los abusos que sufren por motivos de género, y ello tanto antes del ingreso en el CIE como una vez retenidas. Según el Informe de la Asociación Pro Derechos Humanos de España de 2013, en los centros son objeto de provocaciones y propuestas indecentes y obscenas por parte de los policías, y se han reportado también agresiones sexuales. De igual modo resulta especialmente grave que se hayan constatado casos en que una denuncia de agresión sexual por parte de mujeres en situación administrativa irregular pueda acabar con la agredida en un CIE, como denuncia la Fundación Aspacia en el estudio "Violadas y expulsadas. Entre el miedo y la desprotección. Mujeres en situación irregular frente a la violencia sexual en España”.

Que la legislación no proteja a estas mujeres frente a la expulsión -como sí hace actualmente la LOEx con las extranjeras en situación irregular que sufren violencia de género y las víctimas de trata -cuestión diferente es la eficacia práctica de tales previsiones, como advertimos anteriormente- les disuade de presentar la eventual denuncia, provoca su indefensión y favorece su invisibilidad, y, lógicamente y en consecuencia, todo lo anterior conlleva la impunidad de los agresores.

Como advertimos al inicio de este apartado terminaremos este punto haciéndonos eco de algunas propuestas y recomendaciones de organizaciones sociales involucradas en este ámbito que merecen ser destacadas a la luz del panorama descrito. Las recomendaciones de CEAR en el mencionado Informe del año 2009 -relativo a los CIE de Madrid, Málaga y Valencia- clasifican ciertas medidas en tres grupos atendiendo a la urgencia de su adopción: de máxima prioridad, urgentes y adicionales de especial relevancia.

Es prioritario para esta organización depurar las responsabilidades en los casos de tortura y tomar las medidas pertinentes para evitar que ocurran en el futuro. Es urgente resolver el problema de acceso a los baños por las noches, dotar a los centros de un equipo de trabajo social, favorecer el contacto con el exterior, clarificar el régimen disciplinario, la entrega efectiva de los certificados de estancia y de información relativa a los derechos y deberes de los internos, incluyendo el derecho de asilo, garantizar un sistema de peticiones y quejas efectivo, permitir que el interno pueda dirigirse al Juez o al fiscal, el traslado de los enfermos psiquiátricos a centros adecuados, contar con un sistema eficaz de mediadores y traductores y mejorar la calidad de los servicios médicos. Y por último, constituyen medidas adicionales de especial relevancia proveer de mobiliario básico a las celdas, así como de lavandería y tendedero, proporcionar a los internos ropa, calzado y útiles de aseo, mejorar el régimen y los espacios de visita de los familiares y la alimentación, y finalmente proveer espacios de lectura y para la oración.

Junto con las propuestas anteriores y más recientemente, Pueblos Unidos recoge en el Informe de 2013 "Criminalizados. Internados. Expulsados" una serie de recomendaciones dirigidas a diferentes agentes involucrados: 
Al Ministerio del Interior. En lo referido al Reglamento recomienda, a modo de ejemplo, que se apruebe un Reglamento sobre los CIE que suponga, de manera efectiva, un cambio de modelo en el régimen de internamiento, superando el modelo meramente policial existente en la actualidad. En cuanto al uso del internamiento, se recomienda, entre otras medidas, que se emplee, con carácter general, el procedimiento ordinario para sancionar los supuestos de estancia irregular y se imponga sanción de multa en los supuestos de mera estancia irregular. Y respecto a las condiciones de internamiento, que haya garantía de acceso al expediente administrativo e información por parte de los internos y de las entidades sociales autorizadas por los mismos y que se refuercen las medidas para prevenir y controlar los posibles abusos policiales en el CIE.

A los Juzgados y al Consejo General del Poder Judicial. Entre otras propuestas, se solicita que se valore por parte de las autoridades judiciales la "expulsabilidad" de las personas que se pretende internar y que los Juzgados de Instrucción no autoricen internamientos colectivos de personas recién llegadas a nuestro país, sino que siempre lo hagan de acuerdo con un análisis caso a caso de la situación, valorando las circunstancias particulares de cada persona interna.

Al Consejo General de la Abogacía de España y a los abogados. Se recomienda, entre otras medidas, que se refuerce la formación continua en derecho de extranjería y que se designe el mismo letrado del turno de oficio para el procedimiento de expulsión y para la autorización del internamiento.

A la fiscalía. Se sugiere que el Ministerio Fiscal tenga una mayor intervención en frontera, a los efectos de la identificación de posibles menores no acompañados y víctimas de trata y que haya reconocimientos forenses de determinación de la edad acordes con las recomendaciones del Defensor del Pueblo, pruebas médicas y establecimiento de una horquilla de edad en beneficio del posible menor.

A la sociedad en su conjunto. Y pide finalmente al conjunto de los ciudadanos que se esfuercen en visibilizar la realidad de los CIE, que apuesten por el valor de la hospitalidad, encarnándolo en prácticas cotidianas y que impulsen la creación de un proyecto piloto de recogida de buenas prácticas en alternativas al internamiento, a través de una comisión mixta con diversos actores sociales.

\section{EL NUEVO REGLAMENTO DE FUNCIONAMIENTO Y RÉGIMEN INTERIOR DE LOS CENTROS DE INTERNAMIENTO DE EXTRANJEROS}

Como señalábamos anteriormente, tras casi treinta años de existencia y el prolongado incumplimiento del plazo de seis meses establecido por la Ley Orgánica 2/2009 para la aprobación de una normativa de desarrollo sobre la materia, ha sido adoptado el Real Decreto $162 / 2014$, de 14 de marzo, por el que se aprueba el Reglamento de funcionamiento y régimen interior de los centros de internamiento de extranjeros (RD en adelante).

Tal vez la novedad más importante, que se traduce de su articulado y se clarifica en el Preámbulo, sea la diferenciación en la organización y actividad diaria de dos ámbitos que responden a finalidades diferentes. Por un lado, la seguridad de los centros y de las personas que en ellos se encuentran, que se atribuye al Cuerpo Nacional de Policía; y por otro lado, la faceta asistencial, aunque constataremos más adelante que en la nueva normativa la prestación de servicios de asistencia sanitaria y sociales sigue siendo competencia del Ministerio del Interior, labor que sigue además supeditada al control del director, funcionario policial. 
Por lo que respecta a la estructura de la norma, consta de siete Títulos, que abordan los siguientes aspectos: Título I. Disposiciones generales, características y estructura orgánica de los centros; Título II. Estatuto jurídico de los extranjeros internados; Título III. Procedimientos de actuación: ingresos, salidas, traslados y conducciones; Título IV. Normas de convivencia y régimen interior; Título V. Formación del personal del centro y mecanismos de control e inspección; Título VI. Medidas de seguridad; Título VII. Participación y colaboración de las organizaciones no gubernamentales.

Mientras algunas medidas constituyen una mera prolongación del sistema y legitiman su continuidad como modelo de gestión policial de carácter racista, otras sí constituyen alguna novedad -al menos en el papel- que, de cumplirse en la práctica, podrían ayudar a mejorar las condiciones de vida dentro de los CIE, favorecer la transparencia y paliar la impunidad existente. Pero en cualquier caso deviene fundamental la aplicación práctica de estas medidas, porque de nada sirve repetir las medidas y derechos ya contemplados en la legislación vigente (muchas reivindicaciones constituyen incumplimientos de la legislación actual, no necesariamente reclamaciones dirigidas a que se contemplen nuevas medidas), de nada sirve que se mejore el rango jerárquico de la norma o que se establezcan mejoras legislativas si después no se cumple la legislación ni se traduce en avances en el día a día de los internos en los centros.

Aprovechamos para cuestionar también que las acciones sanitarias, sociales y culturales sigan dependiendo en última instancia de la aprobación del director del centro -decisiones que deberían recaer en el personal especializado y no en un funcionario policial que no ha sido formado en temas sanitarios y sociales-, y que se establezca la posibilidad de realizar conciertos con entidades privadas para la prestación de ciertos servicios, como el sanitario. Destacaremos a continuación algunos aspectos del articulado que entendemos merecen especial atención.

Establecimientos públicos de carácter no penitenciario sometidos a control judicial. Respetando el orden sistemático de la propia norma, vuelve a insistir el legislador en el art. 1 $\mathrm{RD}$ en que los CIE (una vez descartado el cambio de denominación a Centros de estancia controlada de extranjeros -CECE-, como se llegó a valorar) son "establecimientos públicos de carácter no penitenciario" en los que "el ingreso y la estancia (...) tendrá finalidad preventiva y cautelar, y estará orientado a garantizar la presencia del extranjero durante la sustanciación del expediente administrativo y la ejecución de la medida de expulsión, devolución o regreso".

Seguirán siendo centros sometidos a control judicial de acuerdo con el art. 2 RD, desde la decisión judicial de internamiento hasta la puesta en libertad; y además, corresponde conocer al Juez competente para el control de la estancia en el centro de las peticiones y quejas que planteen los internos en cuanto afecten a sus derechos fundamentales, pudiendo también visitar los centros cuando conozca algún incumplimiento grave o lo considere conveniente.

Instalaciones y dependencias. El art. $7 \mathrm{RD}$ aborda las instalaciones y medios básicos y alguno de sus apartados parece que vienen a solucionar -al menos de forma explícita en el papel- ciertas deficiencias anteriormente denunciadas en este contexto. Exige en primer lugar que "todas las instalaciones y dependencias deberán satisfacer las condiciones de accesibilidad e higiene y estar acondicionadas de manera que el volumen de espacio, ventilación, agua, alumbrado y calefacción se ajusten a las normas de habitabilidad y a las condiciones climáticas de la localidad donde se halle ubicado el centro. Asimismo, deberán estar equipadas del mobiliario suficiente para hacerlas aptas para el uso a que se destinan”. 
Además, el apartado 5 del art. 7 RD señala que “deberán existir instalaciones adecuadas para la realización de actividades de ocio, entretenimiento y deportivas, así como un patio para el paseo de los internos" y, el apartado 6 indica que "los centros deberán contar con espacio y medios suficientes para el almacenaje seguro de los equipajes y efectos personales de los internos, incluyendo la custodia de dinero en efectivo y objetos de valor". Finalmente, el apartado 7 asegura que "los centros deberán contar con un número suficiente de teléfonos públicos para su uso por los internos en los horarios y condiciones que se determinen".

Separación de internos. El apartado 3 del art. $7 \mathrm{RD}$ aborda la delicada cuestión de la separación de los internos según sus perfiles, aunque la redacción dada a la norma no garantiza que determinados aspectos a mejorar se vayan a corregir. Si bien esta previsión empieza obligando a que los centros dispongan de módulos independientes para permitir la separación por sexos de los internos, a continuación empieza a condicionar ciertos aspectos de la organización interna.

En primer lugar, se limita a decir que "se procurará que los internos que formen una unidad familiar estén juntos y tengan en su compañía a sus hijos menores, facilitándoles, en la medida de lo posible, alojamiento separado que garantice un adecuado grado de intimidad". Tal previsión resulta contraria a jurisprudencia constitucional sobre el derecho fundamental a la intimidad personal (art. 18 Constitución Española) y al art. 17.2 de la Directiva 2008/115/CE antes mencionada, que se expresa en términos imperativos: "2. A las familias internadas en espera de expulsión se les facilitará alojamiento separado que garantice un grado adecuado de intimidad".

En segundo lugar, señala el RD que "se procurará que las instalaciones permitan la separación de los condenados, internados en virtud del art. 89.6 del Código Penal, o que tengan antecedentes penales, de aquellos otros que se encuentren internos por la mera estancia irregular en España".

Asistencia sanitaria. A diferencia de lo anterior, la redacción proporcionada a la norma sobre asistencia sanitaria en el apartado 4 del art. 7 RD sí obliga a dotar a los centros de un servicio de atención sanitaria con disponibilidad de personal, instrumental y equipamiento necesario para la atención permanente y de urgencia de los internos. Asimismo deberán delimitarse las dependencias necesarias para la permanencia de los extranjeros internados que, según el informe emitido por el facultativo, aconseje su separación del resto de los internados, medida que deberá ser comunicada inmediatamente al Juez competente para el control de la estancia de los extranjeros en el centro.

$\mathrm{El}$ art. 7.4 $\mathrm{RD}$ ha de completarse con lo establecido por el art. $14 \mathrm{RD}$, específicamente dedicado al servicio de asistencia sanitaria. Señala dicho precepto que "en cada centro existirá un servicio de asistencia sanitaria bajo la responsabilidad de un médico perteneciente a la Administración General del Estado, que estará auxiliado en sus cometidos por, al menos, un ayudante técnico sanitario o diplomado o graduado universitario en enfermería".

Además de la asistencia sanitaria, médica y farmacéutica, corresponde también a este servicio inspeccionar los servicios de higiene y proponer a la Dirección para su aprobación las medidas sobre la alimentación, "teniendo en consideración las adaptaciones necesarias en caso de enfermedad o creencia religiosa, o de aquella especial que, a juicio del facultativo, requieran determinados extranjeros". De igual modo le corresponde supervisar el aseo e higiene de los extranjeros internados, así como de sus ropas y pertenencias, la higiene, calefacción, iluminación y ventilación de las dependencias, los servicios de control periódico de la salubridad y la prevención de epidemias y adopción de medidas de aislamiento de pacientes infecto-contagiosos. 
Asistencia social, jurídica y cultural. Junto con el servicio de asistencia sanitaria son asimismo relevantes los servicios de asistencia social, jurídica y cultural. El art. 15 RD señala que los servicios de asistencia social y cultural serán atendidos por trabajadores sociales, pero puntualiza que estarán bajo la dependencia directa del director, a quien le corresponderá aprobar los planes de actuación. Añade esta disposición una cuestión esencial relacionada con la denuncia de falta de formación del personal de los centros: "en todo caso, el personal integrante de los servicios de asistencia social deberá contar con formación o conocimientos adecuados en materia de derechos humanos, extranjería, protección internacional, mediación intercultural, así como de enfoque de género y violencia contra las mujeres". Siendo esto positivo, preocupa aún más la formación de los funcionarios policiales, que comentaremos más adelante.

La asistencia social y cultural se orientará fundamentalmente a la resolución de los problemas surgidos a los extranjeros internados $\mathrm{y}$, en su caso, a sus familias, como consecuencia de la situación de ingreso, en especial los relacionados con interpretación de lenguas (no parece ser el mejor lugar para prever la asistencia de intérpretes), relaciones familiares con el exterior o tramitación de documentos. Asimismo, frente a la ausencia de privacidad como uno de los aspectos a mejorar, señala este art. que los centros dispondrán de dependencias que aseguren la confidencialidad de la orientación jurídica que preste al interno su abogado.

Derechos de los internos. El art. 16 RD contempla los derechos de los internos. Con anterioridad, éstos se recogían en el art. 27.2 de la Orden Ministerial de 1999 y en el art. 62 bis LOEx. En relación con este último precepto, redactado por el apartado sesenta y seis del art. único de la Ley Orgánica 2/2009, de 11 de diciembre, de reforma de la Ley Orgánica $4 / 2000$, se ha criticado que contemple un elenco de derechos "carente de armonía". Junto a derechos básicos fundamentales como el derecho a la vida y a la salud, a la asistencia jurídica y a ser asistido por un intérprete, se relacionan otros que no alcanzan ese rango, como el derecho a la visita de familiares o a la asistencia social, lo que hubiera exigido una agrupación de derechos más sistemática, teniendo en cuenta por ejemplo que las vulneraciones de unos y otros cuentan con canales de protección diferenciados (García, 2006:1290). Sobre esta consideración no parece que nada haya cambiado en la nueva regulación, y de hecho la relación de derechos no aporta prácticamente novedades respecto a regulaciones anteriores, pero sí observamos alguna mejoría que puede ser interesante mencionar.

Por ejemplo, se establece que los internos deberán ser designados por su nombre, y no por su número de expediente como se ha denunciado en alguna ocasión, lo cual es sin duda contrario a la dignidad de toda persona. Se clarifica también que el extranjero tiene derecho a que se le facilite el ejercicio de los derechos reconocidos por el ordenamiento jurídico y en especial cuando se solicite protección internacional (sigue sin establecerse que se le debería proporcionar de oficio información sobre la posibilidad de solicitar tal protección) o cuando sea víctima de violencia de género, de trata de seres humanos o de violencia sexual. Asimismo las mujeres embarazadas tienen derecho a recibir un seguimiento médico especial.

Reingreso en un CIE. El siguiente aspecto que queremos destacar es el relativo al reingreso en los centros. Va de suyo que permitir que un extranjero entre en un CIE en repetidas ocasiones desvirtúa la excepcionalidad que debe informar la adopción de esta medida. Pero además entendemos que existe una incongruencia entre el texto del RD y la LOEx por lo que respecta a la posibilidad de ordenar que un extranjero vuelva a ser encerrado en un CIE por las mismas causas en las que se basó un internamiento anterior, 
siendo más garantista el régimen existente hasta la fecha que el contemplado en el nuevo Reglamento, de rango inferior.

Indica el art. 21.3 RD tras señalar el carácter judicial del internamiento y el tiempo máximo de estancia de sesenta días que se podrán solicitar nuevos ingresos del extranjero si obedecen a causas diferentes por la totalidad del tiempo legalmente establecido, y que "podrá solicitarse un nuevo internamiento del extranjero, por las mismas causas que determinaron el internamiento anterior, cuando habiendo ingresado con anterioridad no hubiera cumplido el plazo máximo de sesenta días, por el periodo que resta hasta cumplir éste". Por el contrario, el art. 62.2 LOEx establece que no podrá acordarse un nuevo internamiento por cualquiera de las causas previstas en un mismo expediente. Lo mismo establece el art. 246.3 in fine del Reglamento de extranjería de 2011.

Certificado de estancia. La cuestión anterior se encuentra estrechamente relacionada con la obligación de proveer al extranjero con un certificado de estancia al abandonar el centro obligación prevista ya en la Orden Ministerial de 1999 pero frecuentemente incumplida-, con el que pueda probar que ya estuvo internado en un CIE.

En el art. $37 \mathrm{RD}$ se establece que el cese del ingreso será adoptado por el director del centro en los casos enumerados en dicho precepto. Entre ellos, cuando se tenga constancia de que la expulsión, devolución o regreso no podrá llevarse a efecto. En el momento de la salida se devolverán al interno todas las pertenencias previamente depositadas y la nueva norma insiste en que las autoridades deberán entregarle un certificado del periodo de internamiento.

Si la salida se ha producido para ejecutar la expulsión y ésta no ha podido llevarse a efecto, se procederá al reingreso del extranjero durante el plazo que reste hasta el máximo legalmente autorizado siempre que no exista constancia de la imposibilidad de llevar a cabo la repatriación, en cuyo caso deberá ser liberado.

Normas de convivencia y régimen interior. De acuerdo con el art. $39 \mathrm{RD}$, los horarios, las actividades y demás medidas de régimen interior (actos de aseo personal, visita médica, comidas, visitas externas, comunicaciones telefónicas, etc.) dependerán del director del centro, previa consulta de la junta de coordinación, lo que sin duda puede dar lugar a agravios comparativos según los centros al no establecerse un régimen uniforme para todos los centros del territorio español más allá de los parámetros mínimos contemplados en los siguientes preceptos. Según el art. 40 RD la jornada diurna deberá adaptarse a las estaciones del año y la climatología sin que en ningún caso pueda comenzar antes de las ocho horas ni terminar después de las veinticuatro horas. Deberán garantizarse ocho horas de descanso nocturno y, al menos, cuatro horas de paseo diurno.

Son especialmente importantes en este contexto las visitas de familiares y otras personas. Asegura el art. 42.1 RD que "éstas se desarrollarán sin más limitaciones que las derivadas de la custodia de las personas internadas, de su seguridad y salud, de la capacidad de las instalaciones y del régimen y gobierno del centro". Existirá libertad de comunicación dentro del horario fijado pero "cuando las solicitudes de comunicación excediesen de la capacidad de las instalaciones podrán limitarse los días de cada semana o la duración de las visitas, sin que puedan ser inferiores a treinta minutos para visitantes salvo que se trate de familiares, abogados, representantes diplomáticos o consulares". Es igualmente relevante el apartado 5 del art. 42 RD, según el cual "se garantizará el derecho a la intimidad en el desarrollo de estas comunicaciones que, salvo resolución judicial en contrario, se realizarán con vigilancia meramente visual".

La última consideración que destacaremos del régimen interior hace referencia a las comunicaciones con el exterior. El Reglamento establece que en las zonas de uso común que se determinen por la dirección se habilitarán teléfonos de uso público sometidos a la tarifa 
vigente, que correrá a cargo de los interesados. Parece por omisión que sigue sin permitirse el uso de teléfonos móviles, ni de faxes, ni Internet, por lo que las posibilidades de comunicación con el exterior son muy limitadas, por no hablar de las dificultades que supone para los internos no tener acceso a sus terminales (si no conocen de memoria los números de teléfono de sus allegados y abogados, por ejemplo) y las discusiones entre los propios internos para usar los pocos teléfonos disponibles cuando lo necesitan, o los problemas con los que se encuentran sus familiares para poder hablar con ellos porque comunican muy frecuentemente.

En este mismo contexto criticar por último que el art. 31.2 RD establezca que "se permitirá al extranjero comunicarse telefónicamente de forma gratuita la primera vez, con su abogado y con un familiar u otra persona de su confianza residentes en España”. Esta especificación constituye una traba añadida para aquellos extranjeros que se encuentren solos en España y tengan a esa persona de confianza en el extranjero.

Formación y reglas de conducta del personal del centro. Se trata de un tema de especial relevancia para la materia por la cantidad de quejas y denuncias a las que ha dado lugar y que constituye además una novedad respecto de la regulación vigente. El art. 48 RD prevé en primer lugar la celebración periódica y continuada de actividades formativas dirigidas a los funcionarios al servicio de los centros, policías y demás personal, en las materias de Derechos Humanos, régimen de extranjería, seguridad y prevención, así como de enfoque de género y violencia contra las mujeres.

Se consigna además explícitamente en el art. 49 RD que tales funcionarios deberán observar un trato correcto en sus relaciones con los internos, garantizarán la integridad, dignidad e imparcialidad en sus actuaciones y evitarán realizar o que se realicen por terceros cualquier práctica abusiva, arbitraria o discriminatoria. Termina el precepto obligando al personal a ir identificado de forma visible, como vienen reclamando las organizaciones para favorecer la instrucción e investigación de las denuncias por abuso policial.

Libros-registro. La nueva normativa establece la obligación de llevar libros-registro donde constará el control de diferentes circunstancias. El art. 51 RD indica que se llevarán preferiblemente informatizados, al menos, los siguientes libros-registro: de entradas y salidas de internos, de traslados y desplazamientos, de visitas, de correspondencia y de peticiones y quejas. El responsable de estos libros es el secretario del centro, quedando bajo su custodia y conservación.

Entendemos que esta medida puede favorecer la transparencia si se lleva a efecto correctamente, pero nos preguntamos al mismo tiempo respecto del libro-registro de peticiones y quejas si se está respetando realmente la confidencialidad de las personas internas cuando el mismo se custodia por el secretario del director. La misma duda surge en relación con las quejas que se presenten ante el propio director o en el Registro del centro para que se remita al órgano destinatario (art. 19.1 y .2 RD).

Medidas de seguridad. Éste es posiblemente uno de los aspectos más sensibles y controvertidos de la función policial. La ejecución de las medidas de seguridad corresponde a la unidad de seguridad, labor que, de acuerdo con el art. 53.2 RD, "se regirá por los principios de proporcionalidad, oportunidad y congruencia, y se llevará siempre a cabo con absoluto respeto al honor, dignidad y demás derechos fundamentales de las personas”. El art. $54 \mathrm{RD}$ contempla a continuación la posibilidad de incluir para la vigilancia del interior el control por circuito cerrado de televisión de todas las dependencias salvo dormitorios y baños. Esta medida aparentemente positiva presenta no obstante dos inconvenientes. Primero, se establece como una mera posibilidad; y segundo, es precisamente en esos 
espacios (dormitorios y baños) donde se denuncian abusos por no haber cámaras de vigilancia, por lo que se da continuidad a tales espacios de impunidad.

Por otro lado, en este contexto resulta relevante mencionar los registros personales de los internos con las garantías exigidas por el Tribunal Constitucional en la STC 17/2013, de 31 de enero. El art. 55.2 RD permite los registros personales, incluso con desnudo integral si fuera indispensable, en situaciones excepcionales y cuando sea necesario para garantizar la seguridad del centro o existan motivos racionalmente fundados para creer que el interno pudiera esconder objetos o sustancias prohibidas o no autorizadas. El registro deberá realizarse por personal del mismo sexo del interno, en lugar cerrado y preservando en todo momento la dignidad e intimidad, siendo necesaria la autorización del director salvo situaciones urgentes o de extrema necesidad. Se dejará constancia documental del examen y se proporcionará una copia de dicho escrito al Juez competente del control del centro.

Forman parte también de las medidas de seguridad las medidas coercitivas contempladas en el art. $57 \mathrm{RD}$, esto es, las acciones de contención física o su separación preventiva "en habitación individual". Se podrá adoptar este tipo de medidas con el fin de evitar actos de violencia o lesiones propias o ajenas, impedir posibles actos de fuga o daños en las instalaciones de los centros y ante la resistencia al personal "en el ejercicio legítimo de su cargo o función".

De acuerdo con el art. 57.3 RD, estas medidas deberán acordarse por el director mediante resolución motivada, que será notificada previamente por escrito al interesado en un idioma que comprenda y será remitida copia a la autoridad judicial que autorizó el internamiento (debería haberse previsto la comunicación al Juzgado de control, que es el más indicado para supervisar estas circunstancias y no así otros jueces que pueden encontrarse en localidades diferentes al CIE con dificultades en tomar declaración a los internos).

Todo ello salvo razones de urgencia, como era de esperar, en cuyo caso tales medidas podrán adoptarse de forma inmediata, informando al interno verbalmente y dictando la correspondiente resolución después de haber sido adoptada la medida. Corresponderá al Juez acordar el mantenimiento, modificación o revocación de estas medidas (art. 57.7 RD).

La nueva norma señala además que esta medida se ejecutará en "habitaciones destinadas al aislamiento provisional (...) de análogas características a las ordinarias" (art. 57.5 RD) debería haberse exigido además que se instalaran cámaras de video vigilancia-, que deberá adoptarse "durante el tiempo estrictamente necesario" (art. 57.2 RD -debería haberse establecido un plazo máximo-) y que no podrá adoptarse cuando se trate de mujeres gestantes, mujeres que hubiesen terminado el embarazo durante los nueve meses siguientes, madres lactantes, mujeres con hijos en el centro y enfermos convalecientes de enfermedad grave salvo que pueda derivarse un peligro inminente para su integridad o la de otras personas (art. 57.6 RD).

Nos gustaría denunciar por último que el Reglamento "insinúa” en el art. 11.4 RD que los efectivos del Cuerpo Nacional de Policía que formen parte de la unidad de seguridad podrán portar armas de fuego dentro del CIE, desde el momento en que dicha disposición indica que "en aquellas zonas o espacios en las que razones de seguridad así lo aconsejen, se podrá prestar servicio sin armas de fuego". Esta decisión supone un grave retroceso con respecto a la situación actual, criminaliza aún más a los internos y no se justifica en absoluto. Los comportamientos violentos de algunas personas internas constituyen casos individuales y excepcionales en los que deben aplicarse medidas particulares.

Participación y colaboración de las organizaciones no gubernamentales. Las organizaciones sociales y de apoyo a los inmigrantes han jugado un papel determinante en este contexto, no sólo sacando a la luz los abusos y las violaciones de Derechos Humanos 
cometidos en los CIE que hemos ido relatando en este estudio, sino también por la asistencia y el apoyo material, jurídico y psicológico que han venido prestando de forma individualizada y desinteresada a los extranjeros internos en los mismos.

El art. 62 bis LOEx, proclama como un derecho de los internos "entrar en contacto con organizaciones no gubernamentales y organismos nacionales, internacionales y no gubernamentales de protección de inmigrantes" y permite visitar los centros a "las organizaciones constituidas legalmente en España para la defensa de los inmigrantes y los organismos internacionales pertinentes", aunque reiteradas denuncias han visibilizado las dificultades para poner en práctica estas disposiciones.

Ahora, la nueva norma habla en el art. 58 RD y en la Disposición Adicional cuarta de "entidades colaboradoras" para referirse a aquellas organizaciones que hayan suscrito un convenio para la prestación de servicios en un determinado campo (sanitario, social o de otro tipo), y en el art. $59 \mathrm{RD}$ regula la intervención de "las organizaciones constituidas legalmente en España para la defensa de los inmigrantes o dedicadas al asesoramiento y ayuda a solicitantes de protección internacional y los organismos internacionales de semejante naturaleza", que podrán ser autorizados por el director para visitar el CIE y entrevistarse con los internos, en los horarios y condiciones establecidos en las normas de régimen interior.

Se impone para poder entrar una serie de trabas burocráticas. La organización ha de solicitar una acreditación previa al director que acompañará de una copia de sus estatutos, el certificado de pertenencia a la misma de los miembros que soliciten acceder al centro y la explicación del objeto de la visita. Las acreditaciones que se concedan serán personales e intransferibles y deberán entregarse en el plazo máximos de 72 horas desde que se haya comprobado que se cumplen todos los requisitos. Los internos también podrán pedir una entrevista con una determinada organización, debiendo el centro comunicarlo a la misma, la cual podrá realizar la visita siguiendo las instrucciones anteriores.

Terminaremos este apartado señalando que como consecuencia de la aprobación del Reglamento se ha dictado recientemente la Circular 6/2014 de la Dirección General de la Policía de 11 de julio de 2014 en la cual se establecen los "Criterios para solicitar el ingreso de ciudadanos extranjeros en los centros de internamiento". La Circular recoge aspectos interesantes relacionados con algunas cuestiones comentadas en este trabajo. Por ejemplo, recuerda que existen otras medidas cautelares que pueden ser adoptadas "en sustitución" del internamiento, como la presentación periódica ante el instructor o la retirada del pasaporte, y exige una valoración sobre la viabilidad real de la expulsión y las circunstancias personales genéricas y específicas del extranjero para formar elementos de juicio sobre la petición de internamiento. También requiere a los instructores para que consulten enlaces Web de ACNUR con el objetivo de detectar países en riesgo a los que no se debiera expulsar a los extranjeros.

Pero al mismo tiempo lo más grave es que en la propia Circular se reconoce que ha habido un "número considerable de peticiones de internamiento (...) de extranjeros cuya situación no siempre aconseja adoptar dicha medida cautelar", lo que según la Campaña Estatal por el cierre de los CIE constituye "una autoinculpación en toda regla". Considera también esta plataforma que la Circular simplemente vuelve a dejar por escrito lo que debería haberse cumplido, sobre todo desde la jurisprudencia constitucional mencionada en este trabajo que ya configuró el internamiento como una medida excepcional, y que "si no se ha cumplido la legalidad hasta ahora no ha sido por falta de una Circular, sino por una absoluta falta de voluntad política e interés en el respeto de los derechos humanos de las personas migradas". 


\section{VALORACIÓN FINAL}

Probablemente la valoración final haya quedado evidenciada a lo largo de todo el trabajo. No puede ser otra que sumarnos a las voces que exigen el cierre de estos centros. No cumplen con la finalidad para la que fueron creados y los internos sufren física $\mathrm{y}$ psicológicamente una medida desproporcionada e injustificada en muchos casos, sobre todo personas que carecen de antecedentes penales y tienen arraigo en España.

Las organizaciones sociales son pesimistas en cuanto al eventual impacto positivo de la nueva regulación. Asegura la Campaña por el cierre de los CIE (Dossier de prensa de marzo de 2014) que "la aprobación del Reglamento no aporta ninguna garantía de que hechos como los denunciados hasta ahora no vuelvan a repetirse" y que puedan "denunciarse y judicializarse para visibilizar un horizonte en el que pueda superarse esta opacidad e impunidad". Denuncian además que existen omisiones en el Reglamento que favorecerán que puedan volver a producirse graves situaciones como la muerte de Samba Martine en el CIE de Aluche de 2011 -cuyo caso se ha reabierto recientemente-, ya que no se recoge la obligación de que el traslado de personas desde los CETI a los CIE vaya acompañado del traslado y entrega del historial médico del extranjero.

Tendremos que esperar para ver cómo se reflejan las mejoras puestas de relieve, que requieren necesariamente mayor inversión pública. El Ministerio del Interior ha confirmado que el coste anual de funcionamiento de los CIE es de 8,8 millones de euros, y se prevé mejorarlo con otros 3 millones de euros procedentes de ajustes en el presupuesto del propio Ministerio. Igualmente ha anunciado inversiones por importe de 2,5 millones de euros, sin necesidad de incrementar el presupuesto del Ministerio, y dentro del marco financiero plurianual de la Unión Europea para Asuntos de Interior para el período 2014-2020 se contempla la posibilidad de financiación comunitaria para su modernización.

A la espera de que estos centros acaben desapareciendo, continuaremos atentos a la información que sigan proporcionando nuestros ojos dentro de los CIE y denunciando los abusos que se cometan tras sus muros.

\section{BIBLIOGRAFÍA}

CAMPO CABAL, J. M. (2001). “Artículo 62. Ingreso en centros de internamiento". En: J. M. Campo Cabal (coord.) Comentarios a la Ley de Extranjería (LO 4/2000 reformada por LO 8/2000). Madrid: Civitas.

FERNÁNDEZ ARÉVALO, L. (2013). "Artículo 62. Ingreso en centros de internamiento". En: P. Aguelo Navarro (dir.) (2013). Comentarios a la Ley de Extranjería. Madrid: Colex.

GARCÍA CATALÁN, J. M. (2002). Infracciones, sanciones y procedimiento en la Ley y el Reglamento de Extranjería. Barcelona: Atelier.

GARCÍA RIVAS, N. (2006). "Artículo 62 bis. Derechos de los extranjeros internados". En: C. Esplugues Mota (coord.) Comentarios a la Ley de Extranjería. Valencia: Tirant lo Blanch.

JARRÍN MORÁN, A., RODRÍGUEZ GARCÍA, D. y DE LUCAS, J. (2012). "Los centros de internamiento de extranjeros en España: Origen, funcionamiento e implicaciones jurídico-sociales". En: Documentos CIDOB, 26: 1-16.

MIRALLES SANGRO, P. (2012). "Democracia, Derechos Humanos y Constitución exigen el cierre inmediato de los centros de internamiento de extranjeros (CIE)". En: Revista de Derecho UNED, 10: 731-742. 
NOGUERAS DORADO, F. M. y RODRÍGUEZ CANDELA, J. L. (2001). "Las infracciones en materia de extranjería y su régimen sancionador". En: M. Moya Escudero (coord.) Comentario sistemático a la Ley de Extranjería (LO 4/2000 y LO 8/2000). Granada: Comares.

ORTEGA MARTÍN, E. (2005). Manual de Derecho de extranjería. Madrid: Europea de Derecho.

VALLUY, J. (2005). “Introduction: l'Éurope des camps. La mise à l'écart des étrangers". En : Cultures et conflits, 57: 5-11.

\section{Otras fuentes consultadas}

CAMPAÑA ESTATAL POR EL CIERRE DE LOS CIE. Dossier de prensa sobre el Reglamento de la Campaña por el cierre de los CIE y otros Informes y estudios sobre la situación en los CIE (consultado 29.07.2014): http://cerremosloscies.wordpress.com/

CAMPAÑA ESTATAL POR EL CIERRE DE LOS CIE. Respuesta a la nueva Circular de la Policía Nacional para ingreso en los CIE, de 29 de julio de 2014 (consultado 29.07.2014):

$\mathrm{http} / /$ ciesno.wordpress.com/2014/07/29/respuesta-a-la-nueva-circular-de-la-policia-nacional-para-

ingreso-en-los-cie/

INFORME MNP 2013. Disponible en (consultado 29.07.2014):

http://www.defensordelpueblo.es/es/Mnp/InformesAnuales/InformeAnual_MNP_2013.pdf

INFORME PUEBLOS UNIDOS 2013 "Criminalizados. Internados. Expulsados" (consultado 29.07.2014):

http://www.entreculturas.org/files/imagenes2014/marzo/InformeCIE2013.pdf

MARTÍNEZ ESCAMILLA, M. (dir.) (2013). Mujeres en el CIE: género, inmigración e internamiento (consultado 29.07.2014): http://eprints.ucm.es/21399/3/Mujeres_en_el_CIE_Marga_v_3.pdf

FUNDACIÓN ASPACIA (2013), Violadas y expulsadas (consultado 29.07.2014):

http://violadasyexpulsadas.org/img/informe.pdf

MINISTERIO DEL INTERIOR, Presentación del RD 162/2014 (consultado 29.07.2014):

http://www.interior.gob.es/documents/10180/1703283/REGLAMENTO_CIE.pdf/ff3f967a-a71e-4622-

$8 \mathrm{f} 14-220043 \mathrm{~b} 27 \mathrm{a} 04$

\section{Breve currículo:}

\section{Carmen Azcárraga Monzonís}

Profesora Contratada Doctora de Derecho Internacional Privado del Departamento de Derecho internacional "Adolfo Miaja de la Muela" de la Universitat de València (España). Se licenció en Derecho en 2002 por la misma Universidad, obteniendo el Premio extraordinario de Licenciatura. Cursó el Máster en Abogacía Internacional Práctica de la Universidad de Murcia en 2006. Es Doctora en Derecho Internacional desde 2007 y autora de trabajos científicos sobre diferentes materias. Ha realizado estancias de investigación en diferentes países, habiendo trabajado además en distintas ocasiones en la Conferencia de La Haya de Derecho Internacional Privado (Holanda). Es la coordinadora de la Red Jurídica Internacional REDCompara desde su creación en 2010. 